\title{
Assessment of the Psychological Well-Being of Teachers in the Covid-19 Pandemic
}

\author{
Vaccaro $\mathrm{M}^{1,2 *}$ and Lombardo $\mathrm{G}^{1,2}$ \\ ${ }^{1}$ Associazione Qui ed Ora, Catanzaro (CZ), Italy \\ ${ }^{2}$ Associazione Un mondo 3d, Beinasco (TO), Italy
}

*Corresponding author: Vaccaro M., Psy. D; Ph.D. .; Associazione un mondo 3d, Italy, Via Mirafiori, 25, Beinasco, Torino; Tel: 3489132738--Email: marianna.vaccaro@yahoo.it

\section{Research Article \\ Volume 4 Issue 5}

Received Date: September 22, 2020

Published Date: October 14, 2020

DOI: $10.23880 /$ eoij-16000256

\section{Abstract}

The Covid-19 pandemic has led to changes in the habits of human beings with repercussions on psychological well-being from an emotional and affective point of view. So far, research in the literature has focused on the critical elements of distance learning from a connection point of view and software used. It is necessary to expand the research aimed at assessing the impact that the pandemic has had on the psychological well-being of teachers who have been asked not only to change their habits but at the same time the working context and teaching tools. The research was born as an observational study through structured interview, conducted on a sample of 38 randomly selected teachers, representative of the Calabria region. Each respondent was subjected to a questionnaire which explored the perceived psychological well-being and demographic descriptors, such as age, sex, marital status, city of residence, profession, city where they work, years of work, experience, duration of the working week, and the impact that the pandemic has had on their work. To assess the quality of life at work over the last 30 days, the Hundall Self Report proQOL - Professional Quality of Life Scale Questionnaire (2009) was used, consisting of 30 questions on a Likert scale (from 1"never" to 5 "very often"), which can be traced back to 3 dimension: Compassion Fatigue, Burnout and Compassion Satisfaction. The results have shown that a sudden and radical change in one's habitual behaviors, as well as the way and context of work, have led teachers to have a reduced perception of the quality of life in one's work environment. The man by nature has enchored to his daily habits and asking him to change his routine behavior involves a decompensating in the perception of his quality of life as demonstrated by the study conducted.

Keywords: ProQOL; Quality of Life; Teachers; Covid-19; Pandemic

\section{Introduction}

The outbreak of the Covid-19 pandemic and the state of lockdown started in Italy on March, 9th 2020, has led teachers to use as the only educational tool the technologies related to the so called Web 2.0, O'Reilly [1] with consequent changes in the way of interrelating with fellow, students, parental, leaders and transmitting educational knowledge. They have started a process of change in their communication and teaching habits in a sudden and rapid way, a task of extraordinary educational importance but which at the same time implies a change both in the role of the teacher and in the way of organizing teaching with consequences on their psychological well-being. An "epochal" change which asked teachers "to learn to teach" through different way from the one they were trained by Hargreaves, et al. [2]; Godson [3]. A complete review of the figure of the teacher and the factor which influence the way in which they relate themselves and their pupils every day is present in the book written by Day C [4] and called "Developing Teachers: the challenges of lifelong learning". Teachers in the months of health emergency have changed the training process from formal to informal by leveraging the potential of Web 2.0 to access and share information, knowledge and good practices through direct consultation of sources and social interaction in online communities of practice. In a shor time they had to adapt 
together with their students to virtual classrooms trying to educate them also to digital citizenship and the conscious and intelligent use of the potential offered by Web 2.0 and mobile technologies with which children relate everyday life [5]. The emergency has caught teachers and learners imprepared to deal with digital didactics, alien in many schools to the daily practice limited to the use of technological tools, such as LIM, tablet and electronic register, which are only a first step towards the real potential offered by new technologies especially to use with ease tools never experienced before often with problems and access limitations. The World Health Organization (WHO) defines the term "mental health" as a state of emotional and psychological well-being in which the individual is able to use his or her cognitive and emotional abilities to exercise his or her role and function within society, to respond to the different needs of daily life, to create satisfactory and mature relationships with others, to participate actively in changes in the environment, to adapt to external conditions and internal conflicts. The evaluation of the quality of life related to health is the subject of continuous research in the clinical field some self-report questionnaires evaluate how much man is satisfied with his life by paying attention to the cognitive component of well-being, others the emotional, one others both components but nothing attests that one is better than the other, because all measure the subjective experience of well-being. People often think about wellness in terms of physical health, diet, exercise weight, management, etc... But it is much more than that. Already in 1999 Ardell defined "wellness" as a dynamic process in continuous evolution given by the holistic integration of mental and spiritual physical well-being, which feeds the body, involves the mind and nourishes the spirit. It is a way of life as well as a professional and personal responsibility. Each worker has an ethical obligation to come for his or her own health and personal well-being. The individual and the environment influence each other. Any change in one person's relationship produces a change in the other. Functional management of the stressful incentives with which each individual relates in everyday life involves maintaining and structuring his or her physical and mental well-being. The positive and negative aspect of work affects the quality of everyone's professional life. People who work to help others responds to individual, national and even international community crises. They may be health care workers, social service workers, teachers, lawyers, police officers, fire-fighters, clergy, transport personnel, rescuers and others. Compassion Satisfaction includes the positive part of the quality of professional life,, while Compassion Fatigue includes the negative part, such as fatigue, frustration, anger and depression, typical of Burnout. They are 2 aspects of the quality of professional life. The Burnout syndrome pathological, outcome of an event experienced by the subject as a stressor, affects people who exercise a helping profession. The term "Burnout" generally translated as "exhausted" was defined by the American psychiatrist Maslach in 1975 [6] as a pathological behavioural response to workers, who have a high relational exchange, a loss of interest in their activities and the people they care for. Syndrome of emotional exhaustion of depersonalization and personal derealisation which can manifest itself in all those professionals who carry out, a professional helper, profession with very strong relational implications as in the case of medical nurses, psychologists and rescuers. Over time additional categories have been included, all those operators who have frequent contact with the public, with the territory, with the users, are therefore not only considered "helper", but also all those workers who carry out professional activities, whose mission in the welfare of people, the increase in quality of life and the solution to their problems. Overburdening of work, lack of control of autonomy and sense of belonging to the group as well as insufficient rewards, fairness or inequalities of retributive justice are some of the main causes of Burnout, which over time doesn't become a problem of the individual but of the whole work context; these manifestations would lead to a progressive deterioration of "commitment", emotions and adaptation between the operator and the work. How each person reacts to the experience of change determines how they perceive quality of life and the whole process of change; each individual has an intuitive understanding of their own wellbeing or malaise and which aspects of their life are more important than others. The quality of life is a multidimensional construct which is affected by the level of adaptation achieved and the organization of the individual's personality; it determines the experiences and meanings to be attributed to one's own change and related events. The concept of quality of life integrates physical-medical aspects with aspirations, personal values, quantity and quality of social relations; it expresses the subjective perception that an individual has of his position in life, in the context of a culture, the set of values in relation to his goals, expectations and concerns. It is a concept of broad spectrum, sensitive to the perception of one's own physical health, emotional psychological health, level of indpendence, social relations and interaction with one's own environmental context [7]. The quality of life is directly related to the ability to react to stressful situations (also known as coping), social support and the level of adaptation achieved [8]. Important factors which influence human behavior are self-regulation and habits. The first is the ability to control one's own impulses, directing one's behavior towards one's goals and values. It isn't simple because it requires energy, resources, time and the brain is always looking for ways to conserve energy and make the human being save his efforts. The latter, on the contrary, as reported in the studies conducted by Duhigg [9], require very little energy because any behavior which can be reduced to a routine doesn't imply devoting strength and time in a process of conscious decision making. Cognitive economics and 
routine behaviors allow the brain to retain the power of selfregulation in order to focus on important decisions in life. Technically, a habit is a recurring behavior, and put in a specific context, which manifests itself automatically, without much awareness or conscious intent and is acquired through frequent repetitions [10]. About $40 \%$ of daily behavior is repeated in the form of habits, it shapes human existence and this mode of functioning and functional for the well-being and quality of life. Insert new routines aren't easy, habitual behaviors are rooted in the human being and are difficult to change [11]. As the behavior is repeated in the same context, the behavior control gradually shifts from being driven internally (e.g. beliefs, attitudes and intentions) to being triggered by situational or contextual signals, such as automatically looking both ways before crossing the street, putting on your seltbelt when entering a car or saying "amen" at the end of a public prayer in church. Wood and Neal [11] describe it as outsourcing behavioural control to contextual signals. There has been a shift from intentional to automatic processes through a wide range of social behaviors [12]. Provided that the context remains the same and the response satisfies the person's objectives, these associations acquire a certain degree of automatism [13]. The context is the environment in which the behavior takes place; the characteristics or cues which trigger the action can be anything from physical objects and previous actions to geographical characteristics or people. Empirical results in various fields suggest that behaviors which repeat constantly in specific contexts are difficult to change. To take new behaviors is a learning process which initially involves difficulty and perception of disturbance in the task and in the new situation you are experiencing. Starting from this, the research hypothesized that a change in one's habits such as distance teaching, initially improvised and unstructured, has led teachers to experience a lower psychological well-being since the dynamics of teaching have inevitably changed. The teacher found himself in the role of tutor who prepares the material, follows the exercises carried out by the student and starts online evaluation practices. The training activity is mediated by computer and Internet connection, therefore the choice of platform can significantly affect the effectiveness of the strategies implemented and the final result [14].

\section{Material and Methods}

\section{Sample}

The sample is composed of a total of 38 elementary school teachers, all of Italian nationality, domiciled in the Calabria region, randomly chosen. Specifically, $84,2 \%$ are women and $15,8 \%$ are men, of which $70 \%$ married. Of them, $5,3 \%$ carry out work for 30 hours, 50\% 24 hours and the remaining $44,7 \% 18$ hours.

\section{Materials, Measures and Procedure}

The tool used to assess the quality of psychological wellbeing perceived by teachers is the Hundall's ProQOL Self Report - Professional Quality of Life Scale, composed of 30 questions on a Likert Scale (from 1 "never" to 5 "very often") to which were added ad hoc structured questions to obtain the demographic information of the sample, such as age, sex, marital status, city of residence, profession, city where you work, years of work experience, duration of the working week and the impact that the pandemic has had on own work. The ProQOL questionnaire is the most commonly used test because it measures the negative and positive effects of helping other people who are suffering and experiencing a climate of suffering, change or trauma. In use since 1995, translated into 26 world languages, it presents secondary scales such as Compassion Satisfaction which is about the pleasure of having the ability to do one's job. Scores for these items below 0.23 describe that the subject may have problems with his work. Burnout is one of the elements of compassion fatigue, associated with feelings of desperation and difficulty in dealing with work and doing one's job in a capable manner. High scores on this scale indicate a higher risk of exhaustion; below 0.23 shows positive feelings about being effective at work. A score above 0.41 reports a belief in not being effective at work. The second component of Compassion Fatigue is the secondary traumatic stress (STS), which refers to work, secondary exposure to extremely or traumatically stressful events. A score above 0.41 describes that the subject devotes a lot of time to think about the stressful events arising and associated with particular work events (Alpha Scale reliability score 0.81). The questionnaire describing the demographic components and the Self Report ProQOL-Professional Quality of Life Scale have both been administered in online mode through drive platform in a completely random way [15-21].

\section{Results}

The sample analysed has fully responded to all items in the questionnaire. As can be seen from figure 1,70.3\% of the subjects don't feel sad, $24.3 \%$ feel sad most of the time and $5.4 \%$ feel so sad and unhappy that they can no longer bear it.

$51.4 \%$ doesn't feel discouraged about the future, while $45.9 \%$ feels discouraged about the future, compared to the usual and $2.7 \%$ doesn't expect anything good from the future. $91.9 \%$ of the subjects doesn't feel failed, $8.1 \%$ instead has failed more than he should have. As far as the loss of pleasure, $43.2 \%$ of the subjects draw the same pleasure as always, from the things he does, $37.8 \%$ doesn't draw more pleasure from the things as he used to be and $18.9 \%$ draws little pleasure from the things which usually amused. For the same subjects, $83.8 \%$ doesn't feel guilty but $13.5 \%$ 
feels guilty for many things he has done or he should have done; $10.5 \%$ of the subjects participating in the research feels as if he was undergoing a punishment and $100 \%$ of the participants doesn't have any suicidal thoughts.

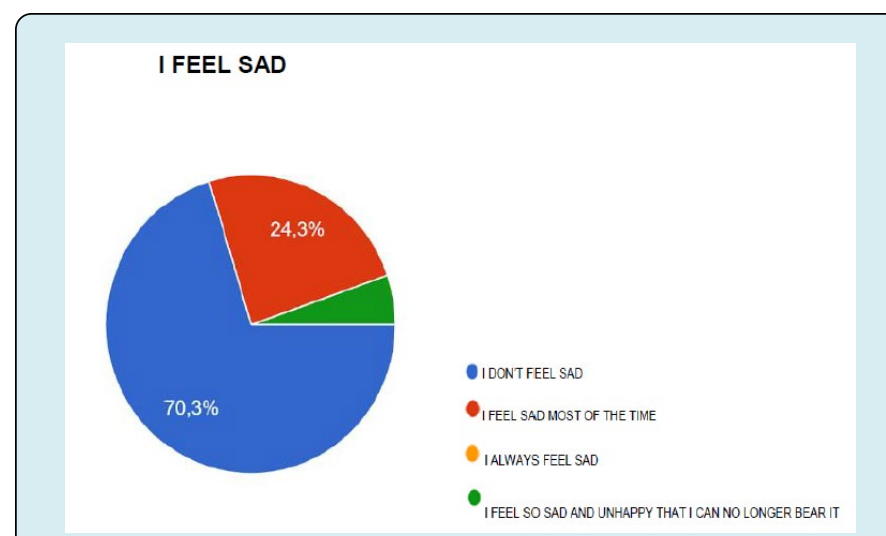

Figure 1: The graph represents the percentage of people interviewed who have experienced feelings of sadness.

In $2.7 \%$ of the sample is disappointed by himself and appears critical for his faults. $10.8 \%$ often feels like crying without succeeding, $63.9 \%$ feels more agitated than usual and $37.8 \%$ is less interested in others or things than others and finds it more difficult than usual to make decisions. As for feeling good or feeling tense and restless, $24.3 \%$ sometimes feels good, $39.5 \%$ almost always and $34.2 \%$ often; $50 \%$ of the subjects instead feels sometimes tense and restless, $23.7 \%$ often, $23.7 \%$ almost never and $2.6 \%$ almost always.

$34.2 \%$ is almost always satisfied with himself, $47.4 \%$ often and $18.4 \%$ sometimes. $42.1 \%$ wouldn't want almost never to be able to be happy as the others seem $31.6 \%$ instead often and $23.7 \%$ often would want to be able to be happy as the others seem. $13.2 \%$ the subjects sometimes felt a failure and $86.8 \%$ almost never feel a failure. As can be seen from the graph in figure $2,34.2 \%$ of the subjects almost never feels rested, $36.8 \%$ sometimes feels rested and $26,3 \%$ often feels rested.

$10.5 \%$ of the subjects almost never feel calm and selfcontrol, $13.2 \%$ sometimes, $36.8 \%$ often feels calm and selfcontrol, $39.5 \%$ almost always feels calm and feels like a master of himself. $44.7 \%$ almost never feels that difficulties accumulate so much that they cannot be overcome, $47.4 \%$ sometimes feels that difficulties accumulate so much that they cannot be overcome, $7.9 \%$ often feels that difficulties accumulate so much that they cannot be overcome. $63.2 \%$ of the subjects sometimes worry too much about things which in reality have importance, $23.7 \%$ almost never and $13.2 \%$ often, as it is possible to observe from the graph of the figure 3.

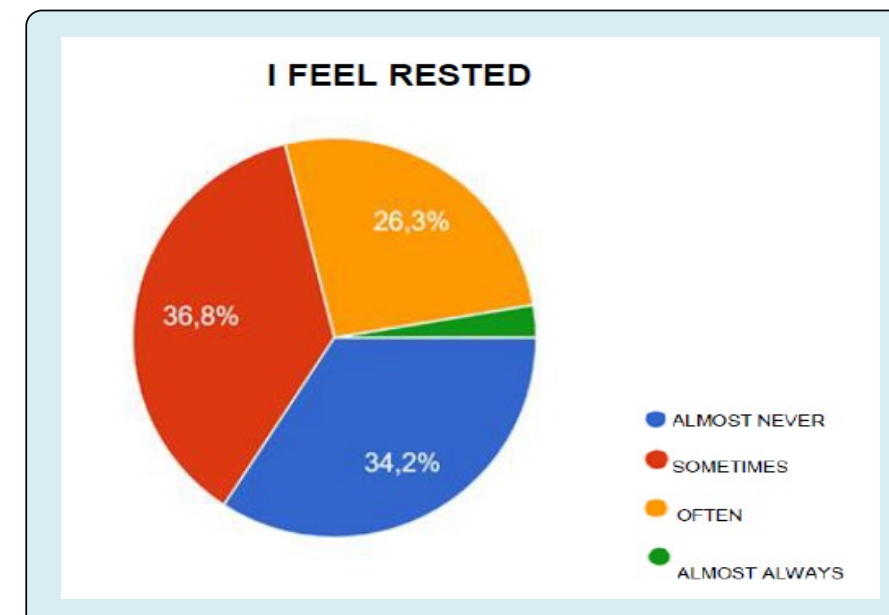

Figure 2: The graph represents the percentage of people interviewed who have experienced feelings of restedness.

I WORRY TOO MUCH ABOUT THINGS, WHICH DON'T REALLY MATTER

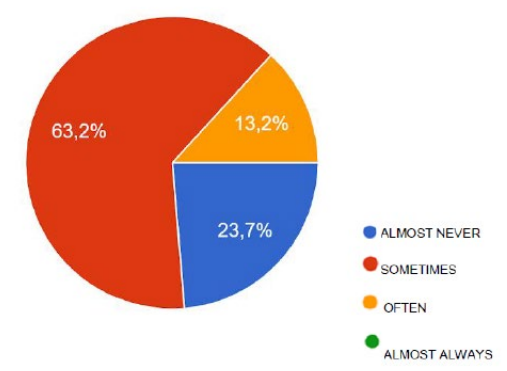

Figure 3: The graph represents the percentage of interviewees who have experienced feelings of worry about unimportant things.

$23.7 \%$ is almost always happy, $34.2 \%$ is sometimes happy and $42.1 \%$ is often happy. $50 \%$ of subjects sometimes have negative thoughts, $36.8 \%$ almost never has negative thoughts, $10.5 \%$ often has negative thoughts and $2.6 \%$ almost always has negative thoughts. $57.9 \%$ almost never lacks selfconfidence, $34.2 \%$ sometimes lacks self-confidence, $7.9 \%$ often lacks self-confidence. $26.3 \%$ of the sample almost always feels confident, $39.5 \%$ often feels confident, $26.3 \%$ almost always feels confident and 5.3\% almost never feels confident. $10.5 \%$ almost never makes decisions easily, $26.3 \%$ sometimes makes decisions easily, $36.8 \%$ often makes decisions easily and $26.3 \%$ almost always makes decisions easily. $65.8 \%$ of the sample almost never feels inadequate, $28.9 \%$ sometimes feels inadequate and $3 \%$ often feels inadequate. $34.2 \%$ sometimes feels happy, $34.2 \%$ often feels happy, $31.6 \%$ almost always feels happy. $73.2 \%$ sometimes has minor thoughts which pass through his mind and annoy, $10.5 \%$ often has minor thoughts which pass through his mind and annoy and $26.3 \%$ almost never has minor thoughts which pass through his mind and annoy. 
UNIMPORTANT THOUGHTS PASS THROUGH MY MIND AND ANNOY ME

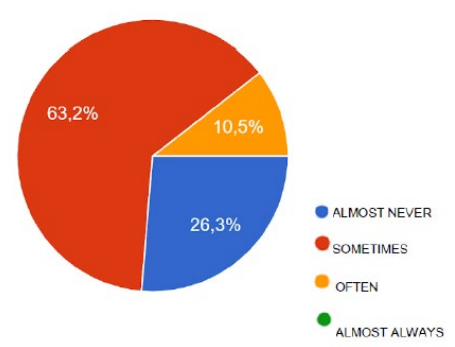

Figure 4: The graph represents the percentage of interviewees who have unimportant thoughts.

$42.1 \%$ of the sample submitted to the research almost never lives disappointments with so much participation that he cannot be taken out of his head, $44.7 \%$ sometimes lives disappointments with so much participation that he cannot be taken out of his head, while $13.2 \%$ often lives disappointments with so much participation that he cannot be taken out of his head. 5.3\% of the sample never is a steady person, $18.4 \%$ sometimes considers himself a steady person, $36.8 \%$ of the sample often considers himself a steady person and $39.5 \%$ of the sample almost always considers himself a steady person. $13.2 \%$ of the subjects almost never becomes tense and disturbed when he thinks to the actual own worries, $55.3 \%$ of the subjects sometimes becomes tense and disturbed when he thinks to the actual own worries, $31.6 \%$ of the subjects often becomes tense and disturbed when he thinks to the actual own worries. $13.2 \%$ of the subjects participating in the research feels not at all safe, $7.9 \%$ feels a bit safe, $57.9 \%$ feels quite safe and $21.1 \%$ feels very safe. Not at all tense $28.9 \%$, a little tense $52.6 \%$, quite tense $15.8 \%$, $3.24 \%$ feels very tense. $31.6 \%$ of the participants to the research for nothing feel under pressure, 39.5\% feels a bit under pressure, $26.3 \%$ feels quite under pressure, $2.6 \%$ feels under a lot of pressure. $10.5 \%$ feels quite calm at all, $31.6 \%$ feels a bit calm, $47.4 \%$ feels quite calm, and $10.5 \%$ feels very calm. $34.2 \%$ of the subjects feels not disturbed at all, $50 \%$ feels a little disturbed, $15.8 \%$ feels quite disturbed, $23.7 \%$ of the subjects feels not disturbed at all. $52.6 \%$ is currently a little concerned about possible misfortunes, $18.4 \%$ is currently quite concerned about possible misfortunes and $5.3 \%$ is currently very concerned about possible misfortunes. $5.4 \%$ feels not at all satisfied, 24.3\% feels a little satisfied, $56.8 \%$ feels quite satisfied and $13.5 \%$ feels very satisfied. $42.1 \%$ of the subjects feel intimidated at all, $34.2 \%$ feels a little intimidated, $18.4 \%$ feels quite intimidated and 5.3\% feels very intimidated. $13.2 \%$ of the subjects feel at ease at all, $21.1 \%$ feels a little bit at ease, $44.7 \%$ feels so much at ease and $21.1 \%$ feels very much at ease. $13.2 \%$ of the subjects feels a little confident, $63.2 \%$ feels quite confident, $23.7 \%$ feels very confident. As observed in figure 5, 28.9\% feels nervous at all, 52.6\% feels a bit nervous, $18.4 \%$ feels quite nervous. $34.2 \%$ gets upset at all, $57.9 \%$ gets a bit upset and 7.9\% gets quite upset. $68.4 \%$ feels undecided at all, $23.7 \%$ feels a little undecided, and $7.9 \%$ feels quite undecided. Not at all relaxed $23.7 \%$, a little relaxed $36.8 \%$, quite relaxed $34.2 \%$ and very relaxed $53.3 \% .10 .5 \%$ of the subjects feel not at all happy, $31.6 \%$ feels a bit happy, $52.6 \%$ feels quite happy, $5.3 \%$ feels very happy. $13.2 \%$ feels not at all worried, $52-6 \%$ feels a bit worried, 26.3\% feels quite worried and $7.9 \%$ feels very worried. $42.1 \%$ feels not at all confused, $44.7 \%$ feels a bit confused, $10.5 \%$ feels quite confused, $2.7 \%$ feels very confused. $34.2 \%$ feels not at all easeful, $28.9 \%$ feels a little easeful, $34.2 \%$ feels quite easeful and $2.7 \%$ feels very easeful. $7.9 \%$ feels not at all good, $26.3 \%$ feels a little good, $60.5 \%$ feels quite good and 5.3\% feels very good.

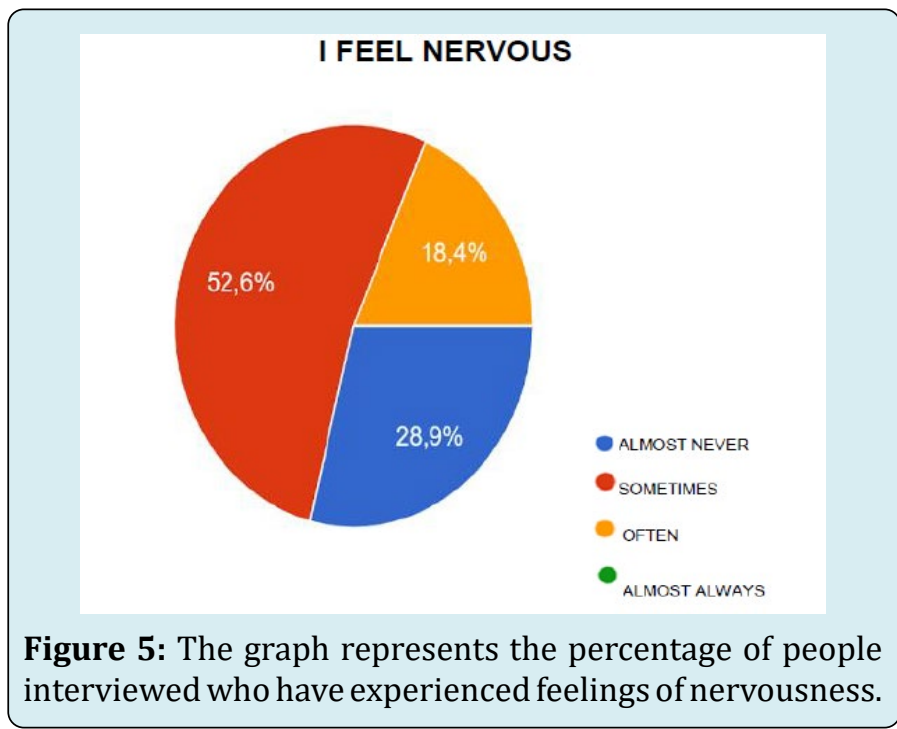

\section{Conclusion}

The Results have shown that asking the human being to change the behaviors rooted in his learning history in a rapid and sudden way in the work environment, involves an initial de-compensation with a consequent lower perception of the quality of life. In the period of COVID-19 health emergency teachers were called to change the way, time and context of work with the introduction of distance learning, finding no problems with their work but with their belief in not being effective at work. (ProQOL score $>0.41$ ). $45.9 \%$ of the interviewed sample felt discouraged in fact about the future compared to the usual and 37.8\% didn't take more pleasure from things as when they did the frontal teaching activity in the classroom and experienced feelings of guilt for many things they did but not as they would have wanted or should have done (13.5\%). 63.9\% of the sample felt more agitated than usual, even $50 \%$ of the subjects felt sometimes expected and restless in front of the PC monitor. The presence of a camera and people outside the school environment led 
teachers to experience a feeling of fear for their work (42.1\%). The descriptive study highlights how teachers experienced a stressful situation during the pandemic, experiencing feelings and beliefs which aren't functional in being able to perform their work qualitatively.

\section{References}

1. O’Reilly T (2006) Web 2.0 Compact Definition: Trying Again.

2. Hargreaves A, Earl L, Moore S, Manning S (2002) Learning to change: Teaching beyond subjects and standards. John Wiley \& Sons.

3. Goodson I (2003) Professional knowledge, professional lives. McGraw-Hill Education, UK.

4. Day C (2002) Developing teachers: The challenges of lifelong learning. Routledge.

5. Trentin G (2009) Teachers and digital natives. Italian Journal of Educational Technology 17(2): 59-59.

6. Maslach C, Leiter MP (1997) The truth about burnout. Jossey-Bass, San Francisco, CA.

7. Secchi G, Strepparava MG (2001) The quality of life in cancer patients: A cognitive approach. European Journal of Internal Medicine 12(1): 35-42.

8. Kimmel PL, Peterson RA, Weihs KL, Simmens SJ, Boyle DH, et al. (1995) Aspects of quality of life in hemodialysis patients. Journal of the American society of Nephrology 6(5): 1418-1426.

9. Duhigg C (2012) The power of habit: Why we do what we do in life and business, Random House.

10. Gigerenzer G (2007) Gut feelings: The intelligence of the unconscious. Penguin.

11. Wood W, Neal DT (2007) A new look at habits and the habit-goal interface. Psychological review 114(4): 848863.

12. McCusker C (2006) Towards understanding loss of control: An automatic network theory of addictive behaviours. Oxford University Press.

13. Verplanken B (2006) Beyond frequency: Habit as mental construct. British Journal of Social Psychology 45(3): 639-656.

14. Palareti F (2020) Distance learning: tools and critical issues. News from Tuscan libraries, Bibelot, 26(1).

15. Bamberg S (2006) Is a residential relocation a good opportunity to change people's travel behavior? Results from a theory-driven intervention study. Environment and behavior 38(6): 820-840.

16. Dewey J (1933) How We Think. A Restatement of the Relation of Reflective Thinking to the Educative Process. DC Heath and Company, Boston, etc.

17. Figley R (2002) Compassion Fatigue: Psychotherapists' chronic lack of self-care. Psychotherapy in practice 58(11): 1433-1441.

18. Hundall Stamm B (2009) Professional quality of life: Compassion satisfaction and fatigue subscales, Version V (ProQOL). Center for Victims of Torture.

19. Maslach C (2003) Burnout: The Cost of Caring. Malor Books, Cambridge, MA.

20. Ouellette JA, Wood W (1998) Habit and intention in everyday life: The multiple processes by which past behavior predicts future behavior. Psychological bulletin 124(1): 54-74.

21. Wood W, Tam L, Witt M G (2005) Changing circumstances, disrupting habits. Journal of personality and social psychology 88(6): 918-933. 